\title{
Corrigendum: Examining the implications of classical budget theories in the local government budgeting process: Union councils in Bangladesh
}

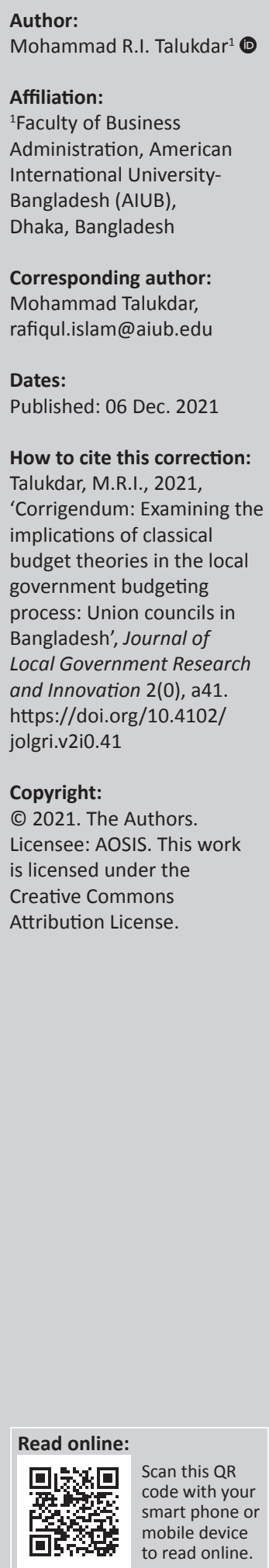

Scan this QR code with your smart phone or mobile device to read online.

In the version of this article initially published, Talukdar, M.R.I., 2020, 'Examining the implications of classical budget theories in the local government budgeting process: Union councils in Bangladesh', Journal of Local Government Research and Innovation 1(0), a22. https: / / doi.org/10.4102/ jolgri.v1i0.22, the source in the footnote for Figure 2 was given incorrectly. The correct footnote should read: 'Source: Adapted from BRAC Institute of Governance and Development (2016), Talukdar (2019) and Talukdar (2020a). Note: Please see the full reference list of the article, Talukdar, M.R.I., 2020, 'Examining the implications of classical budget theories in the local government budgeting process: Union councils in Bangladesh', Journal of Local Government Research and Innovation 1(0), a22. https://doi.org/10.4102/jolgri.v1i0.22, for more information.' instead of 'Source: Please see full reference list of the article (adapted from) BRAC Institute of Governance and Development, 2016, Sharique III, BRAC Institute of Governance and Development, Bangladesh. https://bigd.bracu.ac.bd/projects/sharique-iii/, for more information'.

This correction does not alter the study's findings of significance or overall interpretation of the study results. The author apologises for any inconvenience caused. 